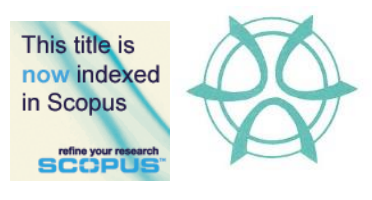

PLANNING MALAYSIA:

Journal of the Malaysian Institute of Planners

VOLUME 18 ISSUE 1 (2020), Page 92 - 101

\title{
NEIGHBOURHOOD QUALITY ASSESSMENT: A VIEW OF TENURE OWNERSHIP AND MOBILITY DECISIONS IN PENANG, MALAYSIA
}

\author{
Hamizah Abdul Fattah ${ }^{1}$, Nurwati Badarulzaman ${ }^{2} \&$ Kausar Ali $^{3}$ \\ ${ }^{1,2,3}$ School of Housing Building and Planning \\ UNIVERSITI SAINS MALAYSIA
}

\begin{abstract}
Most people have experienced a crucial moment of decision during their life course, that of whether to stay over or to move out of their house and neighbourhood. Residential mobility refers to mobility thoughts and intentions, as well as the actual moving behaviours among the residents, which are often triggered by feelings of dissatisfactions, state of disequilibrium or mismatch between the present housing needs and consumption, and the desired housing preferences. Residential mobility is postulated to be influenced by many factors, notably family life cycle (infant to elderly phase), tenure ownership (house owner or renter), housing profile (dwelling features) and quality of the neighbourhood. There is limited study on tenure ownership and factors of neighbourhood quality that can affect mobility decision and residential mobility behaviour. Hence, this study examines mobility decisions based on tenure ownership and neighbourhood quality including physical, social and economic attributes among residents of housing schemes in Penang Island, Malaysia. A questionnaire survey of 717 respondents living in low, medium and high cost housing in the study area revealed that dwelling features, neighbourhood facilities, environment, social interaction and attachment are the major considerations and preferences affecting residential mobility behaviours among residents. The study findings provide insights and guidance on planning for better neighbourhoods to satisfy residents' needs and enhance quality of life.
\end{abstract}

Keyword: neighbourhood quality, residential mobility, mobility decision, tenure ownership 
PLANNING MALAYSIA

Journal of the Malaysia Institute of Planners (2020)

\section{INTRODUCTION}

Residential mobility can be regarded both as an intention to leave, as well as the actual behaviour of residents leaving their house and neighbourhood to relocate elsewhere (de Groot, Mulder, \& Manting, 2011). An intention to leave is considered as residential mobility because the affected residents are involved in residential mobility decision-making, weighting out the wise and subsequently leaving to relocate in another locality (Lu, 1999a). Those neighbourhoods that residents had decided to move into are expectantly well equipped and integrated with public amenities, facilities, transportation, accessibility and safe environment that could enhance residential satisfaction and quality of life.

Neighbourhood quality is a good reflection of the residents' preferences to stay in good neighbourhoods, and vice versa. Positives vibes radiating from neighbourhood quality attributes such as safe environment, accessibility, economic livelihood and social interaction present the residents with a pleasant ambiance of housing and neighbourhood (Petzold, 2017). Residents in turn develop a strong sense of belonging and attachment to their housing and neighbourhood, most possibly with no intention of leaving their neighbourhood in future. Key neighbourhood attributes of physical environment, greenery, facilities, economic livelihood, social interaction, social attachment, dwelling features and utilities can affect mobility decisions and residential relocation choices (Woo \& Morrow-Jones, 2011). Thus, this study aims to examine the linkages between tenure ownership and mobility decisions, and residents' perceptions of their housing and neighbourhood quality. The study is focused on the case of ten residential schemes located in Penang Island, Malaysia

\section{RESEARCH BACKGROUND}

Residential mobility refers to people leaving their house for purposes of relocation, either intra or intercity. Residential mobility among residents can be categorised as (i) mobility thought or intention, and (ii) actual moving (Lee, Oropesa \& Kanan, 1994). Actual moving or mobility happens when there are no explicit physical, social or economic barriers to move (Mulder \& Hooimeijer, 1999). On the other hand, mobility thought or intention refers to the mere act of thinking, considering, planning, willing or expecting to move elsewhere (de Groot, Mulder, Das \& Manting, 2011). Actual mobility and mobility intentions are commonly used as indicators of residential mobility patterns. Studies showed that actual mobility, mobility intention and residential satisfaction are all highly correlated (Woo \& Morrow-Jones, 2011; Parkes \& Kearns, 2003).

Residential mobility is often associated with personal adjustments and changes of residents' housing needs as a result of households' changing composition and profile in a lifetime, from childhood to adulthood and ageing stages (Rossi, 1955). 
Hamizah Abdul Fattah, Nurwati Badarulzaman \& Kausar Ali

Neighbourhood Quality Assessment: A View of Tenure Ownership and Mobility Decisions in Penang, Malaysia

Such profound adjustments may well trigger an action amongst residents to leave the house for residential relocation. Changes in household size and compostion over time indeed show a principle trajectory for residential mobility (Clark \& Huang, 2003; de Groot, Mulder, Das, \& Manting, 2011; Lu, 1999a).

Residential mobility behaviour can be determined using indicators of residential satisfaction. Residents' satisfaction is influenced by a mismatch or lack of interest with current house compared to the desired or preferred housing styles (Kim, Pagliara \& Preston, 2005; Hooimeijer \& Oskamp, 1996). Residents' satisfaction and perception are often driven by self-reflections and experiences that capture their housing needs and future preferences; which prompt mobility intentions and the actual moving (Ghasri \& Hossein Rashidi, 2018). Residents' levels of satisfaction at the micro context of the dwelling itself as well as at the macro view of the neighbourhood perspective can lead to decisions to stay or leave the neighbourhood. Such indicator offers a key predictor of mobility behaviour (Liu, 1999). Neighbourhood quality assessment comprising of physical, social and economic perspectives is a vital measure to determine a comprehensive characteristic of prospective good neighbourhoods (Mohamed Osman et al 2017).

Scholars emphasised that family roots, community connections and resident's satisfaction with their neighbourhood positively affect their decision to stay over instead of leaving (Clark et al., 2017). Arguably, a decision to stay is classified as a non-decision as it is closely related to family life cycle and place attachment (Clark, Duque-Calvache \& Palomares-Linares (2017). This is mainly due to priory on changes in family composition and the bonds they have attached to the existing house and neighbourhood. Hence, mobility decision is closely linked to the judgement of neighbourhood, community and general satisfaction. By the same token, lack of satisfaction with fluctuating housing values and lower quality schools may cause grave concerns among the residents causing them to leave the neighbourhoods (Boschman, 2018).

It is noteworthy that neighbourhood interaction and attachment can evoke and simulate different sets of values among owners and renters. The owners who possess the property would feel more at home residing in their own territory; more so than the renters who are just renting and borrowing the property for an interval. As such, the owners would have a stronger effect on neighbourhood characteristics (Boschman, 2018); while the renters might feel more insecure and uncertain about their main shelter, which may lead them to leave anyway. Life cycle may be a less significant factor on the shift from renting to owning (Sissons \& Houston, 2018) because tenants prefer to relocate in relatively cheaper areas for the sake of saving to eventually own a house. Moreover, relocation timing might influence some residents to become either renters or owners after relocation (Ghasri \& Hossein Rashidi, 2018). 
PLANNING MALAYSIA

Journal of the Malaysia Institute of Planners (2020)

Attributes of neighbourhood quality might differ based on the residents' future desires and aspirations. This is outstanding among residents who are quite hesitant to move or are unsure about moving out of the neighbourhood. A study by Lu (1999) identified inconsistency behaviours by residents who are indecisive about moving out, which indicates a complex situation in mobility. It is interesting to identify differences on perception and satisfaction that influence mobility decisions. A possible explanation is that those residents who intend to move out of their neighbourhood may have some levels of dissatisfactions towards their housing and overall neighbourhood; and vice versa. Tenure ownership, either owners or renters can also influence perceptions on neighbourhood quality assessment.

\section{METHODOLOGY}

Based on the research premise, this study adopted a quantitative approach to investigate linkages between tenure ownership (either owner or renter) and mobility decisions with reference to attributes of neighbourhood quality. The study embarked on a stratified sampling method to select the respondents, namely heads of households residing in ten major neighbourhood schemes in Penang Island. The housing schemes were designated in a 2009 report Profil Bandar Pulau Pinang published by Department of Town and Planning Malaysia and Ministry of Urban Wellbeing, Housing and Local Government Malaysia. The 10 housing schemes are Bayan Lepas, Bayan Baru, Sungai Ara, Balik Pulau, Tanjung Bungah, Tanjung Tokong, Georgetown, Jelutong, Air Itam, and Sungai Dua - Sungai Nibong. These locations are specified as community or town growth centres which are equipped with public facilities, infrastructure and utilities. The types of housing schemes and range of house prices were determined from reports published by Department of Valuation and Property Services Malaysia and National Property Information Centre (NAPIC).

A total of 717 heads of households living in the 10 housing schemes were selected for the study. The identification of respondents (heads of household) was based on two criteria. Criterion 1 refers to tenure ownership, either house owners or house renters. Any status that is irrelevant was disregarded. Criterion 2 refers to future mobility intention, whether respondents had had any intention to move out of their neighbourhood in future. The answer categories were 'Yes - intend to move' or 'No - intend to stay'. Some 323 respondents $(45 \%)$ had mentioned about their plans to leave the neighbourhood; whilst another 394 respondents (55\%) wanted to stay over. The questionnaire survey consists of questions on respondents' perception and satisfaction of the quality of their neighbourhoods with 5-Likert scale options. The option ranges from (1) strongly dissatisfied, (2) dissatisfied, (3) moderate, (4) satisfied to (5) very satisfied. The study employed a descriptive analysis of mean value to determine the level of satisfaction among respondents of different housing cost 
Hamizah Abdul Fattah, Nurwati Badarulzaman \& Kausar Ali

Neighbourhood Quality Assessment: A View of Tenure Ownership and Mobility Decisions in Penang, Malaysia

categories. Independent samples t-test is used to compare the mean scores of different groups of people or conditions (Pallant, 2011). This is important to determine differences in perceptions and satisfactions based on tenure ownership and neighbourhood quality conditions and contexts.

\section{RESULT}

Analysis of levels of satisfaction among the 717 respondents in Table 1 showed that most respondents have moderate levels of satisfaction with regard to neighbourhood quality factors. As can be expected, respondents residing in high cost housing recorded the highest level of satisfaction with their dwelling utility at 3.90 mean value; followed by respondents living in medium cost and low cost dwellings. The lowest mean value of 2.60 was recorded by respondents in low cost housing who were dissatisfied with their neighbourhood greenery. Overall, respondents of high cost housing were comparatively more satisfied with their neighbourhood quality, with an exception of neighbourhood interaction and attachment, with the lowest mean value of 3.12.

Table 1 Level of Satisfaction of Neighbourhood Quality by Housing Costs

\begin{tabular}{lccc}
\hline \multirow{2}{*}{ Factors of Neighbourhood Quality } & \multicolumn{2}{c}{ Levels of Satisfaction (mean value) } \\
\cline { 2 - 4 } & Low cost & Medium cost & High cost \\
\hline Dwelling Features & 3.21 & 3.60 & 3.68 \\
\hline Dwelling Utility & 3.57 & 3.75 & $\mathbf{3 . 9 0}$ \\
\hline Neighbourhood Facilities & 3.39 & 3.36 & 3.50 \\
\hline Neighbourhood Greenery & $\mathbf{2 . 6 0}$ & 3.12 & 3.49 \\
\hline Neighbourhood Public Transportation & 3.25 & 3.55 & 3.29 \\
\hline Neighbourhood Accessibility & 3.24 & 3.51 & 3.41 \\
\hline Neighbourhood Economic Livelihood & 3.17 & 3.34 & 3.42 \\
\hline Neighbourhood Environment & 3.20 & 3.42 & 3.70 \\
\hline Neighbourhood Interaction \& Attachment & 3.17 & 3.19 & $\mathbf{3 . 1 2}$ \\
\hline
\end{tabular}

\section{Factors of Neighbourhood Quality by Tenure Ownership}

Table 2 shows the results of t-test on neighbourhood quality factors by tenure ownership. This analysis involved 525 owners (73.2\%) and 163 renters (22.7\%) in the housing schemes. The other 29 respondents (under 1\%) were excluded from this analysis because their ownership status was considered not relevant, such as company properties and parents /sibling ownership. Study results indicate that owners and renters were significantly different in their perceptions and satisfaction levels toward dwelling features, dwelling utility, neighbourhood greenery, neighbourhood environment, neighbourhood interaction and attachment. Perceptions of owners and renters were significantly different with less than $1 \%$ confidence error for dwelling features, dwelling utility and neighbourhood interaction and attachment. For example, results for dwelling features: (owners $=3.55$; renters $=3.20$ at $4.99 . \mathrm{df}=663, \mathrm{p}=.000$ ). 
PLANNING MALAYSIA

Journal of the Malaysia Institute of Planners (2020)

Table 2 Owners' and Renters' Perceptions of Neighbourhood Quality

\begin{tabular}{|c|c|c|c|c|c|c|c|c|c|}
\hline \multirow{3}{*}{ Factors of Neighbourhood Quality } & \multicolumn{6}{|c|}{ Tenure } & \multirow{3}{*}{$\begin{array}{l}95 \% \text { CI for } \\
\text { Mean } \\
\text { Difference }\end{array}$} & \multirow{3}{*}{$\mathrm{t}$} & \multirow{3}{*}{ df } \\
\hline & \multicolumn{3}{|c|}{ Owners } & \multicolumn{3}{|c|}{ Renters } & & & \\
\hline & $\mathrm{M}$ & SD & $\mathrm{n}$ & M & SD & $\mathrm{n}$ & & & \\
\hline Dwelling Features & 3.55 & .713 & 525 & 3.20 & .683 & 163 & $.210, .483$ & $4.99 * *$ & 663 \\
\hline Dwelling Utility & 3.79 & .633 & 525 & 3.48 & .640 & 163 & $.191, .436$ & $5.01 * *$ & 663 \\
\hline Neighbourhood Facilities & 3.45 & .615 & 525 & 3.33 & .598 & 163 & $-.006, .229$ & 1.86 & 663 \\
\hline Neighbourhood Greenery & 3.13 & 1.03 & 525 & 2.92 & .911 & 163 & $.023,388$ & $2.21^{*}$ & 355 \\
\hline Neighbourhood Transportation & 3.31 & .966 & 525 & 3.44 & .955 & 163 & $-.319, .053$ & -1.40 & 663 \\
\hline Neighbourhood Accessibility & 3.35 & .655 & 525 & 3.44 & .769 & 163 & $-.226, .062$ & -1.12 & 301 \\
\hline Neighbourhood Economic & 3.32 & .594 & 525 & 3.24 & .683 & 163 & $-.040, .218$ & -1.35 & 304 \\
\hline Neighbourhood Environment & 3.45 & .654 & 525 & 3.29 & .657 & 163 & $.036, .289$ & $2.51 *$ & 663 \\
\hline Neighbourhood Interaction \& Attachment & 3.26 & .585 & 525 & 2.78 & .765 & 163 & $.336, .618$ & $6.67 * *$ & 288 \\
\hline
\end{tabular}

\section{Factors of Neighbourhood Quality by Mobility Decision}

Table 3 shows the results of t-test on the mean scores of neighbourhood quality factors by residents' mobility decision, either 'Yes' (intend to move) or 'No' (intend to stay). Table 3 shows a significant difference on residents' mobility decisions by all factors of neighbourhood quality, with the exception of neighbourhood accessibility. The study found that residents who had decided to stay in their neighbourhood showed a higher level of satisfaction (with less than $1 \%$ confidence error) with their neighbourhood attributes including dwelling features, dwelling utility, neighbourhood greenery, neighbourhood economic, neighbourhood environment and neighbourhood interaction and attachment. For example, the results for neighbourhood greenery: (Yes: $\mathrm{M}=2.92$; No: $\mathrm{M}=3.23$; at significance level: $\mathrm{t}=-3.78, \mathrm{df}=676, \mathrm{p}=.000$ ).

Table 3 Mobility Decision by Neighbourhood Quality

\begin{tabular}{|c|c|c|c|c|c|c|c|c|c|}
\hline \multirow{3}{*}{ Factors of Neighbourhood Quality } & \multicolumn{6}{|c|}{ Mobility Decision } & \multirow{3}{*}{$\begin{array}{l}\text { 95\% CI for } \\
\text { Mean } \\
\text { Difference }\end{array}$} & \multirow{3}{*}{$\mathrm{t}$} & \multirow{3}{*}{ df } \\
\hline & \multicolumn{3}{|c|}{$\begin{array}{c}\text { Yes, } \\
\text { Intend to Move }\end{array}$} & \multicolumn{3}{|c|}{$\begin{array}{c}\text { No, } \\
\text { Intend to Stay }\end{array}$} & & & \\
\hline & $\mathrm{M}$ & SD & $\mathrm{n}$ & $\mathrm{M}$ & SD & $\mathrm{n}$ & & & \\
\hline Dwelling Features & 3.18 & .738 & 323 & 3.71 & .617 & 394 & $-.651,-.426$ & $-9.437 * *$ & 685 \\
\hline Dwelling Utility & 3.51 & .681 & 323 & 3.88 & .590 & 394 & $-.479,-.269$ & $-7.021 * *$ & 697 \\
\hline Neighbourhood Facilities & 3.36 & 699 & 323 & 3.47 & .538 & 394 & $-.211,-.005$ & $-2.064 *$ & 591 \\
\hline Neighbourhood Greenery & 2.92 & .943 & 323 & 3.23 & 1.03 & 394 & $-.471,-.149$ & $-3.78 * *$ & 676 \\
\hline Neighbourhood Transportation & 3.25 & .994 & 323 & 3.42 & .934 & 394 & $-.327,-.012$ & $-2.12 *$ & 715 \\
\hline Neighbourhood Accessibility & 3.31 & .712 & 323 & 3.41 & 677 & 394 & $-.223, .002$ & -1.92 & 715 \\
\hline Neighbourhood Economic & 3.19 & .654 & 323 & 3.39 & .576 & 394 & $-.299,-.096$ & $-3.822 * *$ & 633 \\
\hline Neighbourhood Environment & 3.23 & .684 & 323 & 3.54 & .617 & 394 & $-.410,-.198$ & $-5.639 * *$ & 715 \\
\hline Neighbourhood Interaction \& Attachment & 2.90 & 681 & 323 & 3.36 & .591 & 394 & $-.560,-.351$ & $-8.545^{* *}$ & 628 \\
\hline
\end{tabular}


Hamizah Abdul Fattah, Nurwati Badarulzaman \& Kausar Ali

Neighbourhood Quality Assessment: A View of Tenure Ownership and Mobility Decisions in Penang, Malaysia

\section{DISCUSSION}

Residents' levels of satisfaction with their neighbourhood quality can be considered as a reflection of their socio-economic status in the housing area. The study findings revealed that residents of high cost housing were comparatively most satisfied with their neighbourhood quality, recording higher mean values of satisfaction levels. This may be because residents of high cost housing typically pay much more for their housing, environmental quality, safety, security and accessibility; hence this reflects a better neighbourhood quality provision in the high cost housing (Tan, 2011). Residents of low cost housing are usually satisfied with the most basic necessities of shelter. Furthermore, residents of low cost housing cannot afford spending and investing in housing properties due to financial constraints (de Groot, Mulder, \& Manting, 2011). Nonetheless, the element of neighbourhood greenery consistently scored the lowest mean value of satisfaction among residents of all housing types. This is possibly due to issues of land scarcity and high cost factor. In this study, good economic livelihood in the neighbourhood areas offered an opportunity to residents of low and medium cost housing to set up small businesses in the housing area to enhance income and job opportunities. Overall, all residents showed moderate levels of satisfaction with the neighbourhood quality; and this situation could be upgraded in the future.

In terms of tenure ownership, the study result is consistent with previous studies which showed that owners and renters differ significantly in their perceptions on housing, neighbourhood perspectives and self-esteem (Kleinhans \& Elsinga, 2010). The study results showed that the owners were consistently more satisfied with five neighbourhood attributes, namely dwelling feature, utility, greenery, environment, social interaction and attachment. The renters, on the contrary were more satisfied with neighbourhood transportation and accessibility, but the findings were not significant. This finding is supported by Boschman (2018) and Sissons \& Houston (2018) who also found significant differences among owners' and renters' perceptions and levels of satisfaction in prior studies. However, homeownership do have a significant positive impact on residential stability and neighbourhood environment over time (Aarland \& Reid, 2018). This is because homeownership enhances the residents' satisfaction levels and presents a constant motivation for residents to upgrade and upkeep the neighbourhood (Coenen, Verhaeghe, \& Van de Putte, 2018).

The study also discovered a strong significant difference in mobility decisions in the neighbourhood context. Those residents who had decided to move were dissatisfied with almost all of the neighbourhood quality factors; whereas those who had decided to stay in the neighbourhood mentioned otherwise. This study showed that neighbourhood quality provides a comprehensive approach to assess residents' housing needs and preferences that compliments their socio-cultural norms and lifestyles. The study result is 
PLANNING MALAYSIA

Journal of the Malaysia Institute of Planners (2020)

consistent with that of previous study which highlighted the behaviours of dissatisfied residents who had planned to leave the house and neighbourhood (Kearns \& Parkes, 2003). Their perception of existing neighbourhood is consistent with this study, thus indicating that those who are satisfied with neighbourhood facilities would stay over, and vice versa. The study found that a positive perception of neighbourhood quality is inversely related to low residential mobility as concurred by previous studies (for example: Parkes \& Kearns, 2003).

\section{CONCLUSION}

The paper investigated the intrinsic linkages between residential mobility and neighbourhood quality. It highlighted the people who had decided to move from one neighbourhood to another, their reasons for moving; and their preferences and choice in future housing and neighbourhood. Residents' mobility decisions either to move or to stay, were examined in relation to tenure ownership and perceptions of neighbourhood quality. This study aimed to establish links between mobility behaviour and neighbourhood quality among residents of low cost, medium cost and high cost housing schemes located in Penang Island, Malaysia.

A micro perspective scope derived from family life cycle, tenure ownership and housing profiles have been established in the literature as the underlying reasons influencing residential mobility and future housing preferences. This study has included a macro perspective view of neighbourhood quality in the residential mobility equation. Neighbourhood as a spatial context comprising physical, social and economic features also play a major role that can trigger residential mobility. Attributes of a neighbourhood could be a trend setter in demands for residents to move in or to move out. Residents would weigh related costs and benefits when considering mobility decisions and relocation.

In summation, residential mobility can be regarded as a consistent and pervasive trend and behaviour in cities of the developing countries; hence, it renders a major consideration in the policy development context. It is imperative to develop a policy framework to identify the structural patterns of intracity and intercity residential mobility to determine housing choice and preference. This is crucial in addressing the changing residents' needs and desires of housing characteristics during their life time, as well as in assessing the implications on changing socio-demographic spatial structure of residential areas in the city. 
Hamizah Abdul Fattah, Nurwati Badarulzaman \& Kausar Ali

Neighbourhood Quality Assessment: A View of Tenure Ownership and Mobility Decisions in Penang, Malaysia

\section{REFERENCES}

Aarland, K., \& Reid, C. K. (2018). Homeownership and residential stability: does tenure really make a difference? International Journal of Housing Policy, 1247, 1-27.

Boschman, S. (2018). Individual differences in the neighbourhood level determinants of residential satisfaction. Housing Studies, 33(7), 1127-1143.

Clark, W. A. V, Deurloo, M. \& Dieleman, F. M. (2006). Residential Mobility and Neighbourhood Outcomes. Housing Studies, 21(3), 323-342.

Clark, W. A. V. \& Dieleman, F. M. (1996). Households and Housing: Choice and Outcomes in the Housing Market. Transaction Publishers.

Clark, W. A. V. \& Huang, Y. (2003). The Life Course and Residential Mobility in British Housing Markets. Environment and Planning A, 35(2), 323-339.

Clark, W. A. V., Duque-Calvache, R. \& Palomares-Linares, I. (2017). Place Attachment and the Decision to Stay in the Neighbourhood. Population, Space and Place, 23(2).

Coenen, A., Verhaeghe, P. P. \& Van de Putte, B. (2018). Should I stay or should I go? The association between upward socio-economic neighbourhood change and moving propensities. Environment and Planning A, 50(2), 370-390.

de Groot, C., Mulder, C. H., Das, M. \& Manting, D. (2011). Life Events and The Gap Between Intention to Move and Actual Mobility. Environment and Planning-Part A, 43(1), 48.

de Groot, C., Mulder, C. H. \& Manting, D. (2011). Intentions to Move and Actual Moving Behaviour in The Netherlands. Housing Studies, 26(3), 307-328.

Ghasri, M. \& Hossein Rashidi, T. (2018). Investigating how household's decision on next tenure status affects residential relocation timing. Journal of Housing and the Built Environment, 33(2), 385-408.

Hooimeijer, P. \& Oskamp, A. (1996). A Simulation Model of Residential Mobility and Housing Choice. Netherlands Journal of Housing and the Built Environment, 11(3), 313-336.

Kearns, A. \& Parkes, A. (2003). Living In and Leaving Poor Neighbourhood Conditions in England. Housing Studies, 18(6), 827-851.

Kim, J. H., Pagliara, F. \& Preston, J. (2005). The Intention to Move and Residential Location Choice Behaviour. Urban Studies, 42(9), 1621-1636. Retrieved from

Kleinhans, R. \& Elsinga, M. (2010). "Buy Your Home and Feel in Control” Does Home Ownership Achieve the Empowerment of Former Tenants of Social Housing? International Journal of Housing Policy, 10(1), 41-61.

Lee, B.A., Oropesa, R.S. \& Kanan, J. (1994). Neighbourhood Context and Residential Mobility. Demography, 31 (2), 249-270.

Liu, A. M. M. (1999). Residential Satisfaction in Housing Estates: A Hong Kong Perspective. Automation in Construction, 8(4), 511-524. Retrieved from http://www.sciencedirect.com/science/article/pii/S0926580598000983

Lu, M. (1999a). Determinants of Residential Satisfaction: Ordered Logit vs. Regression Models. Growth and Change, 30(2), 264-287. Retrieved from

Lu, M. (1999b). Do People Move When They Say They Will? Inconsistencies in Individual Migration Behavior 1, 20(5). 
Mohamed Osman, M., Muhamad Yusup, S.W., Abdullah, M.F., Shuid, S. (2017). Housing affordability index for districts in Perak.Advanced Science Letters, 23 (7). pp. 6049-6052.

Mohamed Osman, M., Khalid, N., Muhammad Yusop, S.W. (2017). Housing affordability in the state of Selangor, Malaysia. Advanced Science Letters, 23 (7). pp. 6188 6122. ISSN 1936-6612

Mulder, C.H. \& Hooimeijer, P. (1999). Residential Relocation in a Life Course. In L.G. Wissen \& P. Dykstra (Eds.), Population Issues (p. 159-186). Springer Netherlands.

Pallant, J. (2011). SPSS Survival Manual:A step by step guide to data analysis using the SPSS program. SPSS survival manual 4th ed (Vol. 494). Allen \& Unwin.

Parkes, A. \& Kearns, A. D. E. (2003). Residential Perceptions and Housing Mobility in Scotland: An Analysis of the Longitudinal Scottish House Condition Survey 1991 96. Housing Studies, 18(5), 673-701.

Petzold, K. (2017). Mobility experience and mobility decision-making: An experiment on permanent migration and residential multilocality. Population, Space and Place, 23(8), 1-14.

Rossi, P. H. (1955). Why Families Move: A study in the Social Psychology of Urban Residential Mobility. Free Press Glencoe.

Sissons, P. \& Houston, D. (2018). Changes in transitions from private renting to homeownership in the context of rapidly rising house prices. Housing Studies, 3037, 1-17.

Tan, T. H. (2011). Neighbourhood Preferences of House Buyers: the Case of Klang Valley, Malaysia. International Journal of Housing Markets and Analysis, 4(1), 58-9.

van Eggermond, M.A.B. Erath, A. \& Axhausen, K. W. (2018). Residential search and location choice in Singapore. In 2018 TRB Annual Meeting: Compendium of Papers (pp. 18-01994). The National Academies of Sciences, Engineering, and Medicine.

Woo, M. \& Morrow-Jones, H. A. (2011). Main Factors Associated with Homeowners' Intentions to Move. International Journal of Urban Sciences, 15(3), 161-186. 